\title{
Cinética de fermentação ruminal in vitro, composição química e perfil de ácidos graxos da silagem de bagaço de laranja com fubá de milho
}

\author{
In vitro rumen fermentation kinetics, chemical and fatty acids \\ composition of orange peel silage with corn meal
}

\author{
Fabíola Cristine de Almeida Rêgo ${ }^{1 *}$; Agostinho Ludovico ${ }^{1}$; Lisiane Dorneles de Lima ${ }^{2}$; \\ Lais Belan ${ }^{3}$; Luiz Fernando Coelho da Cunha Filho ${ }^{1}$; Marilice Zundt ${ }^{4}$
}

\section{Resumo}

Objetivou-se com este trabalho, avaliar os efeitos do fubá de milho na silagem de bagaço de laranja in natura. Utilizou-se um delineamento inteiramente casualizado com quatro tratamentos (níveis de fubá de milho) e quatro repetições. Foram utilizados silos experimentais constituídos de baldes plásticos de $12 \mathrm{~L}$ com tampa. Os silos foram abertos aos 90 dias após a ensilagem, sendo avaliadas as perdas por gases e efluentes, $\mathrm{pH}$, composição química, ácidos graxos voláteis e produção de gás in vitro. Os teores de matéria seca (MS), extrato etéreo (EE), carboidratos não fibrosos (CNF) e matéria orgânica apresentaram comportamento linear crescente com a inclusão do fubá de milho. Os teores de fibra em detergente neutro (FDN), fibra em detergente ácido (FDA) e proteína bruta (PB) reduziram com o aumento da proporção de fubá de milho. Com relação a cinética de fermentação ruminal verificouse efeito quadrático crescente da inclusão do fubá de milho no volume final de gás proveniente dos carboidratos não fibrosos (VfCNF) e efeito quadrático decrescente no volume final de gás dos carboidratos fibrosos (VfCF). O bagaço de laranja pode ser conservado na forma de silagem com a inclusão de fubá de milho, permitindo níveis de $\mathrm{pH}$ satisfatórios e minimizando as perdas por efluentes, garantindo boa preservação da silagem. Os teores de 8 e $12 \%$ foram os mais eficientes, garantindo maiores teores de MS, menores teores de FDN e de FDA, maiores teores de CNF, maior produção de volume de gás, podendo ser considerada fonte adequada de volumosos para ruminantes.

Palavras-chave: Carboidratos não fibrosos, perdas por gases, perdas por efluentes, $\mathrm{pH}$

\begin{abstract}
The objective of this study was to evaluate the effects of corn meal in silage orange peel in natura. The experiment has adopted a completely randomized, with four treatments (corn meal levels) and four replications. There were used experimental silos made of bucket of $12 \mathrm{~L}$. Silos were opened at 90 days after ensiling, and evaluated the gases and effluent losses, $\mathrm{pH}$, chemical composition, volatile fatty acids (acetic, propionic, butyric, valeric, isovaleric), and in vitro gas production. The dry matter (DM), ether extract (EE), non-fiber carbohydrates (NFC), and organic matter showed a linear increase with the inclusion of corn meal. The contents of neutral detergent fiber (NDF), acid detergent fiber (ADF) and crude protein $(\mathrm{CP})$ decreased with increasing proportion of corn meal. Regarding the rumen
\end{abstract}

\footnotetext{
${ }^{1}$ Profs. Drs. do Programa de Mestrado em Saúde e Produção de Ruminantes, Universidade Norte do Paraná, UNOPAR, Arapongas, PR. E-mail: fabiola_rego@yahoo.com.br; agostinho@rocketmail.com, luiz.cunha@unopar.br

${ }^{2}$ Dr ${ }^{\mathrm{a}}$ Pesquisadora EM̄MRAPA Caprinos e Ovinos, Sobral, CE. E-mail: lisidelima@gmail.com

${ }^{3}$ Discente de Mestrado do Programa de Mestrado em Saúde e Produção de Ruminantes, UNOPAR, Arapongas, PR. E-mail: laís_belan@hotmail.com

${ }^{4}$ Prof $^{a} \operatorname{Dr}^{a}$ da Universidade do Oeste Paulista, UNOESTE, Presidente Prudente, SP. E-mail: mari@unoeste.br

* Autor para correspondência
} 
fermentation kinetics there was a quadratic effect of increasing inclusion of corn meal in the final volume of gas from the non-fiber carbohydrates (VfCNF) and quadratic effect in decreasing total gas production of the fiber ( $\mathrm{VfCF}$ ). The orange peel can be conserved as silage with the inclusion of corn meal, allowing satisfactory $\mathrm{pH}$ levels and minimize effluent losses, ensuring good preservation of the silage. The levels of 8 and $12 \%$ were the most efficient, ensuring higher levels of DM, lower levels of NDF and ADF, higher levels of NFC, higher production volume of gas, which can be considered a suitable source of forage for ruminants in general.

Key words: Non-fiber carbohydrates, gases losses, effluent losses, $\mathrm{pH}$

\section{Introdução}

O uso da tecnologia de ensilagens de forrageiras e subprodutos da agroindústria são alternativas para atender à demanda crescente de volumosos no período de escassez de forragens, devido a estacionalidade da maioria das espécies tropicais, permitindo assim manter um programa de produção animal sustentável. O Brasil possui grande diversidade de culturas agrícolas que geram muitas vezes grande volume de subprodutos e resíduos nas diferentes regiões do país. Esses por sua vez, na maioria dos casos, podem ser aproveitados na alimentação animal, reduzindo a contaminação ambiental e, ao mesmo tempo, os custos de produção animal, uma vez que a alimentação corresponde a 60-70\% desses custos (DUTRA et al., 1997).

A indústria de suco de laranja produz como subproduto o bagaço de laranja, que corresponde a $50 \%$ do total da fruta; seu valor na alimentação de ruminantes é semelhante ao dos grãos, pois possui alta digestibilidade (VAN SOEST, 1994; SILVA et al., 1997).

$\mathrm{O}$ bagaço de laranja vem sendo utilizado na alimentação de ruminantes, na forma natural (úmido), peletizado ou conservado na forma de silagem. A forma peletizada, entretanto, apresenta excelente valor energético e alta digestibilidade na fração fibrosa, porém seu custo é elevado. Com isso, tem-se buscado alternativas para utilização do bagaço úmido, entre elas, a conservação em forma de silagem.

Para a conservação como silagem, as culturas de milho e sorgo são as espécies mais utilizadas, apresentando em geral altos rendimentos e silagens de boa qualidade, sem necessidade de aditivos para estimular a fermentação e manter a anaerobiose. Entretanto algumas forrageiras e também subprodutos apresentam algumas características indesejáveis no momento da fermentação, como o excesso de água, como é o caso do bagaço de laranja in natura, que apresentou apenas $24,9 \%$ de MS (MACEDO et al., 2007), o que pode ser um inconveniente.

Evidências em pesquisas com materiais de alto teor de umidade têm sugerido que a inclusão de uma fonte de carboidratos durante a ensilagem pode melhorar consideravelmente a qualidade final das silagens, como por exemplo, o uso de farelos de grãos, que possuem baixo teor de umidade. O fubá de milho, por exemplo, é obtido da moagem seca da mistura de gérmen, tegumentos e da parte da porção amilácea da semente, sendo que sua composição química e seu valor nutritivo se assemelham ao farelo ou a quirera de milho (ANDRIGUETTO, 2002). Pesquisas recentes verificaram que a utilização de fubá de milho, é uma boa alternativa para aumentar o teor de matéria seca, reduzir as perdas por efluentes e melhorar o padrão fermentativo da silagem de capim elefante (ANDRADE et al., 2012). Resultados positivos também foram observados com o uso de aditivos protéicos à silagem de bagaço de laranja, garantindo boa preservação da silagem (PINTO et al., 2012).

Este trabalho teve o objetivo de avaliar os teores de inclusão do fubá de milho à silagem de bagaço de laranja in natura, sobre a composição bromatológica, as perdas associadas à fermentação, a produção de ácidos orgânicos da silagem e a cinética de degradação ruminal. 


\section{Material e Métodos}

O experimento foi conduzido em duas etapas, sendo parte dele no laboratório de Bromatologia da Universidade Norte do Paraná, Arapongas-PR, e parte no Laboratório de Análise de Alimentos e Nutrição Animal do Departamento de Zootecnia da Universidade Estadual de Londrina, localizado em Londrina-PR.

O bagaço de laranja in natura foi fornecido pela Corol Cooperativa Agroindustrial Citrus, pertencente à COCAMAR CITRUS, situada na cidade de Rolândia, PR. O delineamento experimental utilizado foi o inteiramente casualizado, com quatro tratamentos, sendo silagem de bagaço de laranja (T0); silagem de bagaço de laranja $+4 \%$ de fubá de milho (T4); silagem de bagaço de laranja $+8 \%$ fubá de milho (T8), silagem de bagaço de laranja $+12 \%$ de fubá de milho (T12). Foram realizadas quatro repetições por tratamento, totalizando 16 silos experimentais.

Os silos experimentais foram confeccionados, utilizando-se baldes plásticos de 12 litros. No fundo de cada balde foi colocado aproximadamente $1 \mathrm{~kg}$ de areia, separados da forragem por um tecido de algodão e uma tela (malha fina), de maneira que possibilitou quantificar os efluentes. Procedeu-se então a compactação do bagaço de laranja nos baldes atingindo a densidade média de $642 \mathrm{~kg} / \mathrm{m}^{3}( \pm 40)$. Para tanto foram colocados entre sete e oito $\mathrm{kg}$ de bagaço de laranja por balde, compactadas em camadas sucessivas de $10 \mathrm{~cm}$ de espessura. Após a compactação do material ensilado os silos foram vedados com tampa plástica contendo uma "válvula de bunsen" adaptada, para permitir o escape dos gases oriundos da fermentação. Os silos foram pesados e armazenados durante 90 dias em local coberto e em temperatura ambiente.

O fubá de milho foi adicionado ao bagaço de laranja antes do enchimento dos baldes nas proporções pré estabelecidas como tratamentos, sendo $0,4,8$ e $12 \%$ da matéria natural, sendo essa massa posteriormente homogeneizada e compactada nos baldes.

As perdas com efluentes foram determinadas por meio da diferença de peso do silo vazio, com areia, tecido e tela plástica antes do enchimento e após a sua abertura, conforme Jobim et al. (2007).

$\mathrm{O} \mathrm{pH}$ da silagem foi determinado utilizando a metodologia descrita por Kung Junior (1996). Foram colhidas amostras de $50 \mathrm{~g}$ das silagens imediatamente após a abertura dos silos, adicionou-se $450 \mathrm{~mL}$ de água deionizada a cada amostra e triturou-se em liquidificador durante um minuto, então aferiu-se o pH utilizando-se um potenciômetro.

Para a determinação dos ácidos orgânicos extraiu-se suco da silagem por meio de prensagem manual do material. Parte deste foi fixado e congelado para posterior determinação dos ácidos orgânicos (acético, propiônico, butírico, isobutírico, valérico e isovalérico), por meio de cromatografia gasosa (ERWIN; MARCO; EMERY, 1961).

Para avaliar a composição bromatológica das silagens, foram colhidas amostras do material in natura, antes da ensilagem (Tabela 1), e após a abertura dos silos. As amostras foram pré secadas em estufa a $55^{\circ} \mathrm{C}$ durante 72 horas, e, logo após trituradas em moinho tipo Willey dotado de peneira com crivos de um mm de diâmetro. Em seguida determinou-se os teores de matéria seca (MS), proteína bruta $(\mathrm{PB})$, fibra em detergente neutro (FDN), fibra em detergente ácido (FDA) e matéria mineral (MM), segundo metodologias descritas por Silva e Queiroz (2006).

Para a determinação dos carboidratos nãofibrosos (CNF) empregou-se a fórmula descrita por Hall (2001), em que $\mathrm{CNF}=100 \%-(\mathrm{PB} \%+$ FDN\% - FDNPB + EE\% + Cinzas\%) e FDNPB é a proteína bruta insolúvel em detergente neutro. Os carboidratos totais (CT) foram obtidos pela equação (SNIFFEN et al., 1992): $\mathrm{CT}=100-(\% \mathrm{~PB}+\% \mathrm{EE}+$ $\%$ cinzas). 
Tabela 1. Composição bromatológica (\% da MS) do bagaço de laranja com quatro teores (\% da MN) de fubá de milho antes da ensilagem.

\begin{tabular}{|c|c|c|c|c|c|c|}
\hline \multirow[b]{2}{*}{ Parâmetros ${ }^{2}$} & \multicolumn{4}{|c|}{ Tratamentos $^{1}$} & \multirow[b]{2}{*}{ Média } & \multirow[b]{2}{*}{$\begin{array}{l}\text { Desvio } \\
\text { padrão }\end{array}$} \\
\hline & $\mathbf{0}$ & 4 & 8 & 12 & & \\
\hline MS & 16,76 & 18,53 & 19,90 & 22,85 & 19,51 & 2,30 \\
\hline MM & 4,76 & 4,17 & 3,69 & 3,40 & 4,01 & 0,53 \\
\hline PB & 7,86 & 7,52 & 7,60 & 7,45 & 7,61 & 0,16 \\
\hline EE & 1,83 & 1,95 & 2,08 & 2,11 & 1,99 & 0,12 \\
\hline FDN & 32,36 & 25,29 & 22,68 & 21,57 & 25,47 & 4,34 \\
\hline FDA & 28,79 & 23,15 & 20,43 & 19,13 & 22,87 & 3,83 \\
\hline $\mathrm{CNF}$ & 53,20 & 61,07 & 63,95 & 65,48 & 60,92 & 4,89 \\
\hline MO & 95,24 & 95,83 & 96,31 & 96,60 & 95,99 & 0,53 \\
\hline
\end{tabular}

${ }^{1}$ Teores $(\%$ da $\mathrm{MN})$ de fubá de milho na silagem de bagaço de laranja in natura

${ }^{2} \mathrm{MS}=$ matéria seca; $\mathrm{MM}=$ matéria mineral; $\mathrm{PB}=$ proteína bruta; $\mathrm{EE}=$ extrato etéreo; $\mathrm{FDN}=$ fibra em detergente neutro; $\mathrm{FDA}=$ fibra em detergente ácido; $\mathrm{CNF}=$ carboidratos não fibrosos, $\mathrm{MO}$ - matéria orgânica.

Fonte: Elaboração dos autores.

O perfil da produção de gases in vitro foi realizado utilizando a metodologia de Theodorou et al. (1994), modificada por Mauricio et al. (1999). Para tanto foram introduzidas $500 \mathrm{mg}$ da amostra em frascos de vidro $(150 \mathrm{ml})$, nos quais foram adicionados $40 \mathrm{ml}$ de solução tampão de McDougal (McDOUGAL, 1949). Na sequência foram adicionados $10 \mathrm{ml}$ de inóculo (oriundo de bovinos fistulados no rúmen), em cada frasco, que foi mantido sob aspersão de $\mathrm{CO}_{2}$ e mantidos a $39^{\circ} \mathrm{C}$ em incubadora. Esses bovinos receberam silagem de milho ad libitum.

Foram incubados também frascos considerados branco, contendo as soluções de incubação sem substrato, para o ajuste das variações existentes. Os frascos foram fechados utilizando-se rolhas de borracha e em seguidas agitados para homogeneização da amostra.

Foram realizadas leituras, da pressão dos gases produzidos e acumulados nos frascos, pela fermentação do substrato, por meio de um manômetro, nos tempos de 1, 2, 3, 4, 5, 6, 9, 12, 18, $24,30,36,48,60,72,84,96$ e 144 horas, e convertida em volume, segundo Mauricio et al. (1999).

Os parâmetros de cinética de fermentação ruminal foram estimados utilizando-se o modelo logístico bicompartimental, ajustado às curvas de produção cumulativa de gases de acordo com Schofield, Pitt e Pell (1994), como segue:

$$
\mathrm{V}(\mathrm{t})=\mathrm{Vf1} /(1+\exp \quad(2-4 * \mathrm{c} \quad *(\mathrm{~T}-\mathrm{L})))+\mathrm{Vf} 2 /
$$
$(1+\exp (2-4 * \mathrm{c} *(\mathrm{~T}-\mathrm{L})))$, em que:

Vfl= volume máximo de gás da fração de carboidratos não estruturais;

$\mathrm{Vf2}=$ volume máximo de gás da fração de carboidratos estruturais;

$\mathrm{C}=$ taxa de degradação $(\% / \mathrm{h})$;

$\mathrm{T}$ e $\mathrm{L}=$ tempos de incubação (horas) e a latência (horas).

As análises estatísticas das variáveis estudadas foram interpretadas por análise de variância e quando significativo à nível de 5\% de probabilidade, foi realizada análise de regressão, utilizando-se o programa (SAS, 2001).

\section{Resultados e Discussões}

As avaliações da composição química do material de origem não foram avaliadas estatisticamente. Os teores de MS, MM, PB, FDN, FDA, EE, CNF e MO do bagaço de laranja antes da ensilagem podem ser visualizados na 
Tabela 1. Os níveis médios observados estão próximos aos padrões encontrados na literatura para o bagaço de laranja in natura, conforme Pereira et al. (2008), que verificaram teores de $24,41 \%$ de MS, 7,4\% de PB, 34,4\% de FDN, $33,0 \%$ de FDA e $3,2 \%$ de EE; e Pinto et al. (2012), relatando teores de $28,1 \%$ de $\mathrm{MS} ; 9,5 \%$ de PB; 31,6\% de FDN, 50,3\% de FDA 1,3\% de EE; $50,3 \%$ de CNF.
Observa-se que ao comparar a composição química do material de origem (Tabela 1) e a silagem do bagaço de laranja (Tabela 2), não ocorreram variações consistentes (menores que $1 \%$ ) nos respectivos teores de MS, MM, PB, FDN, FDA, EE, CNF e MO avaliados. Entretanto ao comparar somente as silagens nos diferentes tratamentos, houve diferença significativa $(\mathrm{p}<0,01)$ para todos os parâmetros avaliados.

Tabela 2. Médias (\% da MS), coeficiente de variação $(\mathrm{CV})$, probabilidade $(\mathrm{P})$, coeficientes de determinação $\left(\mathrm{R}^{2}\right)$ e equação de regressão (ER) dos parâmetros da composição bromatológica em função dos teores de fubá de milho na silagem de bagaço de laranja

\begin{tabular}{cccccccccc}
\hline & \multicolumn{9}{c}{ Tratamentos $^{1}$} \\
\cline { 2 - 5 } Parâmetros $^{2}$ & $\mathbf{0}$ & $\mathbf{4}$ & $\mathbf{8}$ & $\mathbf{1 2}$ & MÉDIA & CV & P & $\mathbf{R}^{\mathbf{2}}$ & ER \\
\hline MS & 16,87 & 18,88 & 20,05 & 22,09 & 19,47 & 2,38 & 0,0001 & 0,94 & 3 \\
MM & 4,78 & 4,16 & 3,71 & 3,43 & 4,02 & 4,34 & 0,0001 & 0,90 & 4 \\
PB & 7,61 & 7,37 & 7,40 & 7,35 & 7,43 & 1,42 & 0,0130 & 0,90 & 5 \\
EE & 1,53 & 1,53 & 2,19 & 2,74 & 2,00 & 11,25 & 0,0001 & 0,84 & 6 \\
FDN & 32,36 & 25,11 & 22,49 & 21,64 & 25,40 & 1,58 & 0,0001 & 0,84 & 7 \\
FDA & 28,67 & 23,41 & 20,84 & 19,44 & 23,09 & 5,30 & 0,0001 & 0,89 & 8 \\
CNF & 53,52 & 61,52 & 64,47 & 65,81 & 61,33 & 3,13 & 0,0001 & 0,86 & 9 \\
MO & 95,22 & 95,84 & 96,29 & 96,57 & 95,98 & 0,18 & 0,0001 & 0,90 & 10 \\
\hline
\end{tabular}

${ }^{1}=$ teores $(\%$ da $\mathrm{MN})$ de fubá de milho na silagem de bagaço de laranja in natura; ${ }^{2}=\mathrm{MS}=$ matéria seca; $\mathrm{MN}=$ matéria natural; $\mathrm{MM}=$ matéria mineral; $\mathrm{PB}=$ proteína bruta; $\mathrm{EE}=$ extrato etéreo; $\mathrm{FDN}=$ fibra em detergente neutro; FDA= fibra em detergente ácido; $\mathrm{CNF}=$ carboidratos não fibrosos; $3-\mathrm{Y}=16,95+0,42 \mathrm{X} ; 4-\mathrm{Y}=4,697-0,113 \mathrm{X} ; 5-\mathrm{Y}=7,539-0,018 \mathrm{X} ; 6-\mathrm{Y}=1,355+0,107 \mathrm{X} ; 7-\mathrm{Y}=$ 30,616-0,869X; 8- Y=27,629-0,756X; 9- Y=55,356+0,995X; $10-\mathrm{Y}=95,306+0,112 \mathrm{X}$.

Fonte: Elaboração dos autores.

Os teores médios de MS das silagens permaneceram, em média, de $19,51 \%$ de MS, portanto abaixo dos $25-35 \%$ preconizado por McDonald, Henderson e Heron (1991). Estes autores afirmam que abaixo de $25 \%$ de MS ocorre maior fermentação de carboidratos solúveis, e favorece o desenvolvimento de Clostridium, produtoras de ácido butírico, além de aumentar as perdas por efluentes.

O aumento linear $(\mathrm{p}<0,01)$ do teor de MS com a inclusão do fubá de milho deve-se ao alto teor de MS do fubá $(92 \%)$ e à sua boa capacidade de retenção de umidade. Esse mesmo comportamento foi observado em pesquisas com silagens de gramíneas de elevado teor de umidade com a inclusão da casca de café, subproduto também com alta capacidade de absorção de água (BERNARDINO et al., 2005; FARIA et al., 2007); e também em silagens de bagaço de laranja com o uso de aditivos protéicos (PINTO et al., 2012).

O teor de PB foi maior na silagem sem o fubá de milho e reduziu linearmente com a inclusão do fubá de milho $(p<0,01)$, conforme era previsto em função do menor teor protéico do aditivo. A média do teor de PB observado nas silagens (7,43\%) corrobora com a literatura, tanto em comparação com a polpa cítrica peletizada (7 a 8\%), nas observações de Rodrigues et al. (2005), quanto na silagem de bagaço de laranja 
in natura (6,8 a 7,2\%), em pesquisa de Ítavo et al. (2000); e 7,17\% em estudo de Pinto et al. (2012). $\mathrm{O}$ teor de PB das silagens (Tabela 2) nos diferentes tratamentos ficou muito próximo ao material in natura (Tabela 1); indicando que o processo de fermentação foi adequado e que não houve elevada degradação da proteína.

Os teores da fração fibrosa das silagens (FDN, FDA) sofreram efeito linear negativo em função dos teores de fubá de milho $(\mathrm{p}<0,01)$; reduzindo à medida que se elevou a adição do fubá, o que pode ser justificado em parte pelos baixos teores de FDN e FDA deste alimento em comparação ao teores observados no bagaço de laranja in natura, bem como por uma possível hidrólise da fração fibrosa através da ação dos ácidos produzidos durante a fermentação (PEDROSO et al., 2008). Outros aditivos também produzem esse efeito, de redução dos teores de FDN e FDA como a adição de inoculantes microbianos (ÍTAVO et al, 2000; SILVA et al., 2010). Essa tendencia pode indicar que os tratamentos utilizados foram eficientes em reduzir as perdas por carboidratos não fibrosos, o que pode ser verificado pelo efeito linear crescente $(p<0,001)$ observado nos teores de CNF com a inclusão do fubá de milho. Os teores médios de CNF do presente estudo variaram de 53,5 a 65,81\%; um pouco superiores aos achados de Pinto et al. (2012).

Não houve diferença nos valores de $\mathrm{pH}$ das silagens (Tabela 3 ), entretanto, todas as silagens apresentaram níveis de $\mathrm{pH}$ dentro do recomendado para uma boa fermentação, entre 3,7 a 4,2 (KUNG JUNIOR; STOKES.; LIN, 2003) e estão em consonância com recentes pesquisas realizada com ensilagem do bagaço de laranja in natura em que o pH oscilou entre 3,41 a 3,49 (PINTO et al., 2012); e entre 3,31 a 3,45 (REGO et al., 2012).

Tabela 3. Média dos AGVs (ácidos graxos voláteis, \% da MS), coeficiente de variação (CV), probabilidade (P) e coeficientes de determinação $\left(\mathrm{R}^{2}\right)$ da silagem de bagaço de laranja com quatro teores de fubá de milho após a abertura do silo.

\begin{tabular}{lccccccccc}
\hline \multirow{4}{*}{ Parâmetros } & $\mathbf{0}$ & $\mathbf{4}$ & $\mathbf{8}$ & $\mathbf{1 2}$ & MÉDIA & $\mathbf{C V}$ & $\mathbf{P}$ & $\mathbf{R}^{\mathbf{2}}$ & $\begin{array}{c}\text { Equação de } \\
\text { regressão }\end{array}$ \\
\cline { 2 - 5 } & & & & & & & & & \\
pH & 3,56 & 3,52 & 3,57 & 3,50 & 3,54 & 1,113 & 0,2425 & - & $\mathrm{Y}=3,54$ \\
Acetato & 13,17 & 8,56 & 8,98 & 8,55 & 9,81 & 18,53 & 0,0005 & 0,44 & 2 \\
Propionato & 0,56 & 0,11 & 0,16 & 0,02 & 0,21 & 139,25 & 0,3992 & - & $\mathrm{Y}=0,21$ \\
Butirato & 0,51 & 0,06 & 0,24 & 0,07 & 0,22 & 199,13 & 0,5157 & - & $\mathrm{Y}=0,22$ \\
Valérico & 0,20 & 0,01 & 0,08 & 0,05 & 0,085 & 158,72 & 0,3806 & - & $\mathrm{Y}=0,085$ \\
Isovalérico & 0,16 & 0,02 & 0,06 & 0,01 & 0,062 & 178,80 & 0,3255 & - & $\mathrm{Y}=0,062$ \\
\hline
\end{tabular}

$1=$ teores $(\%$ da $\mathrm{MN})$ de fubá de milho na silagem de bagaço de laranja in natura; ${ }^{2}{ }_{-} \mathrm{Y}=11,835-0,336 \mathrm{X}$.

Fonte: Elaboração dos autores.

De acordo com a Tabela 3 verificou-se que o ácido em maior concentração nas silagens foi o acético, com média de 9,81\%; e que a silagem controle apresentou o maior valor em comparação aos demais tratamentos (13,17\%). Esses valores estão próximos às observações de Rego et al. (2012), em que os teores de ácido acético foram em média $11,53 \%$ em silagens de bagaço de laranja com diferentes inoculantes microbianos. Este resultado é decorrente dos elevados teores de pectina no bagaço de laranja, o que, segundo Van Soest (1987), favorece a fermentação acética, como ocorreu nesse trabalho. 
Os demais ácidos orgânicos não se diferenciaram entre os tratamentos (Tabela 3). Os níveis de ácido propiônico tiveram uma grande variação entre os tratamentos, sendo de 0,02 a $0,56 \%$; porém estes valores estão dentro dos limites estabelecidos por Roth e Undersander (1995) para uma boa silagem. Os níveis relatados estão dentro dos padrões para materiais com alto teor de umidade, como no capim elefante, valores observados entre 0,06 a $0,23 \%$ (LAVEZZO; LAVEZZO; BONASSI, 1990). O ácido butírico nas silagens com 0 e $8 \%$ de fubá de milho estão abaixo das recomendações para uma silagem ideal, que seria abaixo de $0,1 \%$, conforme Roth e Undersander (1995); entretanto os outros parâmetros avaliados (perdas e pH) não indicam a fermentação secundária nos materiais em questão.
As perdas por gases e efluentes estão demonstradas na Tabela 4. A utilização do fubá de milho na ensilagem do bagaço de laranja alterou significativamente $(\mathrm{P}<0,06)$ as perdas por efluentes, sendo o tratamento de $12 \%$ o que apresentou a menor perda por efluentes. O fubá de milho, na proporção de $12 \%$ representou uma redução de $14 \%$ na quantidade perdida por tonelada, quando comparados à silagem de bagaço de laranja exclusivo. Esses resultados foram similares aos observados por Andrade et al. (2012) que verificaram efeito positivo da adição de fubá de milho na redução das perdas por efluentes em silagens de capim-elefante; da mesma forma Zanine et al. (2006), relataram também redução nas perdas por efluentes adicionando farelo de trigo à silagem de capim elefante.

Tabela 4. Médias das perdas por gases (\% da MS), efluentes (kg/ton MN), coeficiente de variação (CV), probabilidade (P) e coeficientes de determinação $\left(\mathrm{R}^{2}\right)$, equação de regressão (ER)da silagem de bagaço de laranja com quatro teores de fubá de milho após a abertura do silo.

\begin{tabular}{lcccccccc}
\hline & \multicolumn{9}{c}{ TRATAMENTOS $^{\mathbf{1}}$} & & & & E \\
\cline { 2 - 6 } Parâmetros & $\mathbf{0}$ & $\mathbf{4}$ & $\mathbf{8}$ & $\mathbf{1 2}$ & $\mathbf{C V}$ & $\mathbf{P}$ & $\mathbf{R}^{\mathbf{2}}$ & ER \\
\hline GASES & 1,50 & 1,81 & 1,85 & 1,51 & 25,61 & 0,53 & - & $\mathrm{Y}=1,67$ \\
EFLUENTES & 66,8 & 64,7 & 64,9 & 55,0 & 7,80 & 0,06 & 0,22 & 2 \\
\hline
\end{tabular}

${ }^{1}=$ teores $(\%$ da $\mathrm{MN})$ de fubá de milho na silagem de bagaço de laranja in natura; ${ }^{2} \mathrm{Y}=66,45-0,55 \mathrm{X}$.

Fonte: Elaboração dos autores.

As perdas com gases não se diferenciaram entre os tratamentos $(\mathrm{P}>0,01)$ e foram em média, de 1,67\% da MS. Essas perdas podem variar muito conforme o material de origem e os aditivos utilizados. Oliveira et al. (2010) observaram a perda de gases média de 2,9\% da MS em silagens de milho, sorgo, e girassol. Já em silagem de cana-de-açúcar, Schmidt et al. (2011) observaram perda média de $20,2 \%$ da MS com gases e $9,8 \%$ da MN com efluentes.

Os dados referentes à cinética de degradação ruminal (Tabela 5) auxiliam na avaliação dos alimentos, uma vez que a quantidade de gases produzidos de um alimento em incubação reflete a produção de ácidos graxos de cadeia curta, que são a principal fonte de energia dos ruminantes (GETACHEW et al., 2004). O volume final de gás proveniente da degradação dos carboidratos não fibrosos (VfCNF) variou de 180,9 a $206,8 \mathrm{~mL} / \mathrm{g}$ de $\mathrm{MS}$; apresentando tendência quadrática crescente $(\mathrm{p}<0,01)$. O potencial máximo da produção de gases provenientes da fermentação dos CNF foi observado para a silagem com $8 \%$ de inclusão de fubá de milho, enquanto a silagem controle foi a que apresentou o menor potencial, o que pode ser atribuído ao elevado teor de CNF no fubá de milho. Entretanto o que não era esperado foi a redução do volume de gás produzido na silagem com $12 \%$ de fubá de milho, sugerindo novos estudos com maiores 
teores de inclusão de material seco e absorvente em acréscimo a materiais de elevada umidade. Já o volume final de gás proveniente da degradação dos carboidratos fibrosos (VfCF), apresentou comportamento inverso, variando de 122,8 a 108,5 , com tendência quadrática decrescente $(\mathrm{p}<0,01)$ em função da inclusão do fubá de milho, demonstrando redução no potencial de volume de gás até o nível de $8 \%$, com súbito aumento aos $12 \%$, o que também não era esperado.

Tabela 5. Médias de Volume final de produção de gases oriundos da degradação dos carboidratos fibrosos (VfCF) e não fibrosos (VfCNF), suas respectivas taxas de degradação (KdCF e KdCNF) e lag time (L) das silagens com diferentes teores de inclusão de fubá de milho.

\begin{tabular}{|c|c|c|c|c|c|c|c|}
\hline \multicolumn{8}{|c|}{ Tratamentos $^{1}$} \\
\hline Parâmetros & $\mathbf{0}$ & 4 & 8 & 12 & $* \mathbf{C V}$ & $* * \mathbf{R}^{2}$ & $* * \mathbf{E R}$ \\
\hline VfCNF (ml/g MS) & $181,07 \pm 8,43$ & $246,62 \pm 21,8$ & $255,16 \pm 10,0$ & $177,92 \pm 6,48$ & 6,28 & 0,88 & 2 \\
\hline KdCNF (\%/h) & $0,026 \pm 0,003$ & $0,027 \pm 0,001$ & $0,027 \pm 0,001$ & $0,026 \pm 0,0007$ & 6,55 & - & $Y=0,026$ \\
\hline L (horas) & $4,187 \pm 0,256$ & $4,739 \pm 0,241$ & $4,824 \pm 0,377$ & $4,911 \pm 0,166$ & 5,63 & - & $Y=4,65$ \\
\hline VfCF (ml/g MS) & $123,3 \pm 4,41$ & $90,45 \pm 15,2$ & $73,03 \pm 17,14$ & $135,4 \pm 4,22$ & 12,22 & 0,75 & 3 \\
\hline KdCF (\%/hora) & $0,093 \pm 0,005$ & $0,122 \pm 0,017$ & $0,185 \pm 0,113$ & $0,092 \pm 0,004$ & 48,5 & - & $Y=0,126$ \\
\hline
\end{tabular}

${ }^{*} \mathrm{CV}$ - coeficiente de variação $* * \mathrm{R}^{2}$-coeficiente de determinação; *** ER - equação de regressão

$1=$ teores $\left(\%\right.$ da MN) de fubá de milho na silagem de bagaço de laranja; 2 - Y=179,32+26,8X-2,23X $\mathrm{X}^{2}, 3-\mathrm{Y}=127,2-17,49 \mathrm{X}+1,48 \mathrm{X}^{2}$.

Fonte:Elaboração dos autores.

O lag time (L), que corresponde ao tempo de adesão e colonização das bactérias (indispensável para início da degradação via atividade enzimática bacteriana), foi similar entre os tratamentos, indicando que o acréscimo do fubá de milho ao bagaço de laranja não prejudicou a colonização. Este parâmetro está mais relacionado com a degradação da fração fibrosa (MERTENS; LOFTEN, 1980).

A taxa de degradação dos carboidratos não fibrosos (KdCNF) e dos carboidratos fibrosos $(\mathrm{KdCF})$, foi semelhante entre os tratamentos, indicando que a inclusão do fubá de milho não interferiu negativamente na atividade ruminal e na degradação do material.

\section{Conclusões}

O bagaço de laranja pode ser conservado na forma de silagem com a inclusão de fubá de milho, permitindo níveis de $\mathrm{pH}$ satisfatórios, redução das perdas por efluentes, garantindo boa preservação da silagem. Os teores de 8 e 12\% foram os mais eficientes, garantindo maiores teores de MS e de CNF, menores teores de FDN e de FDA, maior produção de volume de gás, podendo ser considerada uma fonte adequada de volumosos para ruminantes em geral.

\section{Agradecimentos}

À fornecedora do bagaço de laranja, Corol Cooperativa Agroindustrial Citrus (pertencente à COCAMAR CITRUS).

\section{Referências}

ANDRADE, A. P.; QUADROS, D. G.; BEZERRA, A. R. G.; ALMEIDA, J. A. R.; SILVA, P. H. S.; ARAÚJO, J. A. M. Aspectos qualitativos da silagem de capimelefante com fubá de milho e casca de soja. Semina: Ciências Agrárias, Londrina, v. 33, n. 3, p. 1209-1218, 2012.

ANDRIGUETTO, J. M. Nutrição animal. São Paulo: Nobel, 2002. 395 p.

BERNARDINO, F. S.; GARCIA, R.; ROCHA, F. C.; SOUZA, A. L.; PEREIRA, O. G. Produção e 
características do efluente e composição bromatológica da silagem de capim-elefante contendo diferentes níveis de casca de café. Revista Brasileira de Zootecnia, Viçosa, v. 34, n. 6, p. 2185-2191, 2005. Suplemento.

DUTRA, A. R.; QUEIROZ, A. C.; PEREIRA, J. C.; VALADARES FILHO, S. C.; THIEBAUT, J. T. L.; MATOS, F. N.; RIBEIRO, C. V. D. M. Efeitos dos níveis de fibra e das fontes de proteínas sobre o consumo e digestão dos nutrientes em novilhos. Revista Brasileira de Zootecnia, Viçosa, v. 26, n. 4, p. 787-796, 1997.

ERWIN, E. S.; MARCO, G. J.; EMERY, E. M. Volatile fatty acid analyses of blood and rumen fluid by gas chromatography. Journal Dairy Science, Champaign, v. 44, p. 1768-1771, 1961.

FARIA, D. J. G.; GARCIA, R.; PEREIRA, O. G.; FONSECA, D. M.; MELLO, R.; RIGUEIRA, J. P. S. Composição químico-bromatológica da silagem de capim-elefante com níveis de casca de café. Revista Brasileira de Zootecnia, Viçosa, v. 36, n. 2, p. 301-308, 2007.

GETACHEW, G.; ROBINSON, P. H.; DEPETERS, E. J.; TAYLOR, S. J. Relationship between chemical composition, dry matter degradation and in vitro gas production of several ruminant feeds. Animal Feed Science and Technology, Amsterdam, v. 111, n. 1-4, p. 57-71, 2004.

HALL, M. B. Recentes avanços em carboidratos nãofibrosos na nutrição de vacas leiteiras. In: SIMPÓSIO INTERNACIONAL DE BOVINOCULTURA DE LEITE,2., 2001, Lavras. Anais... Lavras: Universidade Federal de Lavras, 2001. p. 149-159.

ÍTAVO, L. C. V.; SANTOS, G. T.; JOBIM, C. C.; VOLTOLINI, T. V.; FARIA, K. P.; FERREIRA, C. C. B. Composição e digestibilidade aparente da silagem de bagaço de laranja. Revista Brasileira de Zootecnia, Viçosa, v. 29, n. 5, p. 1485-1490, 2000.

JOBIM, C. C.; NUSSIO, L. G.; REIS, R. A.; SCHIMIDT, P. Avanços metodológicos na avaliação da qualidade da forragem conservada. Revista Brasileira de Zootecnia, Viçosa, MG, v. 36, p. 101-120, 2007. Suplemento Especial.

KUNG JUNIOR, L. Preparation of silage water extracts for chemical analyses. Standard operating procedure. Worrilow: Ed. Delaware: University of Delaware, Ruminant Nutrition Lab., 1996. 32 p.

KUNG JUNIOR, L.; STOKES, M. R.; LIN, C. J. Silage additives. In: BUXTON, D. R.; MUCK, R. E.; HARRISON, J. H. (Ed.). Silage science and technology. Wisconsin: American Society of Agronomy, 2003. p. 305-360.
LAVEZZO, W.; LAVEZZO, E. N. M. ; BONASSI, I. A. Efeito do emurchecimento, formol, ácido fórmico, e solução de "Viher"sobre a qualidade de silagens de capim-elefante, cultivares Mineiro e Vruckwona. Pesquisa Agropecuária Brasileira, Brasília, v. 25, n. 1, p. 125-134, 1990.

MACEDO, C. A. B.; MIZUBUTI, I. Y.; MOREIRA, F. B.; PEREIRA, E. S.; RIBEIRO, E. L. A.; ROCHA, M. A.; RAMOS, B. M.; MORI, R. M.; PINTO, A. P.; ALVES, T. C.; CASIMIRO, T. R. Comportamento ingestivo de ovinos recebendo dietas com diferentes níveis de bagaço de laranja em substituição à silagem de sorgo na ração. Revista Brasileira de Zootecnia, Viçosa, v. 36, n. 6, p. 1910-1916, 2007.

MAURICIO, R. M.; MOULD, F. L.; DHANOA, M. S.; OWEN, E.; CHANNA, K. S.; THEODOROU, M. K. A semi-automated in vitro gás production technique for ruminants feedstuff evaluation. Animal Feed Science and Technology, Amsterdam, v. 79, n. 4, p. 321-330, 1999.

McDONALD, P.; HENDERSON, A. R.; HERON, S. J. E. Biochemistry of silage. 2. ed. Marlow: Chalcombe Publication, 1991. $340 \mathrm{p}$.

McDOUGAL, E. I. Studies on ruminal saliva. 1. The composition and output of sheep's saliva. Biochemical Journal, London, v. 43, n. 1, p. 99-109, 1949.

MERTENS, D. R.; LOFTEN, J. R. The effect of starch on forage fiber digestion kinetics in vitro. Journal of Dairy Science, Savoy, v. 63, n. 9, p. 1437-1446, 1980.

OLIVEIRA, L. B.; PIRES, A. J. P.; CARVALHO, G. G. P.; RIBEIRO, L. S. O.; ALMIDA, V. V.; PEIXOTO, C. A. M. Perdas e valor nutritivo de silagens de milho, sorgosudão, sorgo forrageiro e girassol. Revista Brasileira de Zootecnia, Viçosa, MG, v. 39, n. 1, p. 61-67, 2010.

PEDROSO, A. F.; NUSSIO, L. G.; LOURES, D. R. S. PAZIANI, S. F.; RIBEIRO, J. L.; MARI, L. J.; ZOPOLLATTO, M.; SCHMIDT, P.; MATTOS, W. R. S.; HORII, J. Fermentation, losses, and aerobic stability of sugarcane silages treated with chemical or bacterial additives. Scientia Agricola, Piracicaba, v. 65, n. 6, p. 589-594, 2008.

PEREIRA, M. S.; RIBEIRO, E. L. A.; MIZUBUTI, I. Y.; ROCHA, M. A.; KURAOKA, J. T.; NAKAGHI, E. Y. O. Consumo de nutrientes e desempenho de cordeiros em confinamento alimentados com dietas com polpa cítrica úmida prensada em substituição à silagem de milho. Revista Brasileira de Zootecnia, v. 37, n. 1, p. 134-139, 2008.

PINTO, A. P.; MIZUBUTI, I. Y.; RIBEIRO, E. L. A.; PEREIRA, E. S.; BUMBIERIS JUNIOR, V. H.; PIMENTEL, P. G.; SALMAZO, R.; CARNEIRO, M. 
S. S. Avaliações das silagens de bagaço de laranja e de milho com diferentes aditivos protéicos. Semina: Ciências Agrárias, Londrina, v. 33, p. 3305-3314, 2012. Suplemento 2.

REGO, F. C. A.; LUDOVICO, A.; SILVA, L. C.; LIMA, L. D.; SANTANA, E. W.; FRANÇOZO, M. C. Perfil fermentativo, composição bromatológica e perdas em silagem de bagaço de laranja com diferentes inoculantes microbianos. Semina: Ciências Agrárias, Londrina, v. 33, p. 3411-3420, 2012. Suplemento 2.

RODRIGUES, P. H. M.; BORGATTI, L. M. O.; GOMES, R. P.; MEYER, P. M. Efeito da adição de níveis crescentes de polpa cítrica sobre a qualidade fermentativa e o valor nutritivo da silagem de capim-elefante. Revista Brasileira de Zootecnia, Viçosa, v. 34, n. 4, p. 1138-1145, 2005.

ROTH, G.; UNDERSANDER, D. Silage additives. In: ROTH, G.; UNDERSANDER, D. Corn silage production management and feeding. Madison: Madison American Society of Agronomy, 1995. p. 27-29.

SCHMIDT, P.; ROSSI JUNIOR, P.; JUNGUES, D.; DIAS, L. T.; ALMEIDA, R. de; MARI, L. J. Novos aditivos microbianos na ensilagem da cana-de-açúcar: composição bromatológica, perdas fermentativas, componentes voláteis e estabilidade aeróbia. Revista Brasileira de Zootecnia, Viçosa, v. 40, n. 3, p. 543-549, 2011.

SCHOFIELD, P.; PITT, R. E.; PELL, A. N. Kinetics of fiber digestion from in vitro gas production. Journal of Animal Science, Champaign, v. 72, n. 11, p. 2980-2991, 1994.

SILVA, A. G.; WANDERLEY, R. C.; PEDROSO, A. F.; ASHBELL, G. Ruminal digestion kinetics of citrus peel. Animal Feed Science and Technology, Amsterdam, v. 68, n. 3-4, p. 247-257, 1997.
SILVA, D. J.; QUEIROZ, C. Análise de alimentos: métodos químicos e biológicos. Viçosa, MG: Universidade Federal de Viçosa, 2006.

SILVA, J. M.; CARNAÚBA, J. P.; SILVA, I. O.; ANDRADE, D. E. G. de; MIRANDA, E. C.; AMORIM, E. P. R. Influência de inoculante bacteriano-enzimático sobre a microbiota e qualidade nutricional de silagens de grãos úmidos de milho. Ciência Animal Brasileira, Goiânia, v. 11, n. 1, p. 62-72, 2010.

SNIFFEN, C. J.; O'CONNOR, J. D.; VAN SOEST, P. J.; FOX, D. G.; RUSSELL, J. B. A net carbohydrate and protein system for evaluating cattle diets: II, Carbohydrate and protein availability. Journal of Animal Science, v. 70, n. 11, p. 3562-3577, 1992.

STATISTICAL ANALYSIS SYSTEMS - SAS. User's guide. Version 8. Cary: SAS Institute, 2001. 956 p.

THEODOROU, M. K.; WILLIAMS, B. A.; DHANOA, M., S.; McALlAN, A. B.; FRANCE, J. A simple gas production method using a pressure transducer to determine the fermentation kinetic of ruminant feeds. Animal Feed Science and Technology, Amsterdam, v. 48, n. 3, p. 185-197, 1994.

VAN SOEST, P. J. Soluble carbohydrates and the nonfiber components of feeds. Large Animal Veterinary, v. 42, n. 1, p. 44-46, 1987.

. Nutritional ecology of the ruminant. 2. ed. New York: Cornell University Press, 1994. 476 p.

ZANINE, A. M.; SANTOS, E. M.; FERREIRA, D. J.; OLIVEIRA, J. S.; ALMEIDA, J. C. C.; PEREIRA, O. G. Avaliação da silagem de capim elefante com adição de farelo de trigo. Archivos de Zootecnia, v. 54, n. 208, p. 1-10, 2006. 